\title{
The role of films in medical education: results from a pilot study
}

\author{
O. Varsou ${ }^{1}$, P. L. Wong ${ }^{1}$, V. Wong ${ }^{1}$, I. H. MacDonald ${ }^{1}$, S. P. Qureshi ${ }^{1}$, M. Saleh ${ }^{1}$, J. C. Norris ${ }^{1}$, \\ C. D. Kay ${ }^{1}$ and M. R. Ritchie ${ }^{2}$ \\ ${ }^{1}$ School of Medicine, University of Aberdeen, Polwarth Building, Foresterhill, Aberdeen AB25 2ZD, UK and \\ ${ }^{2}$ Napier University, Edinburgh EH14 1DJ, UK
}

Films may be effective educational tools for raising awareness about various subjects where the themes are portrayed accurately ${ }^{(1)}$. In medical education the combination of films with medical themes and an expert-led discussion on the topic of the film promotes interest and enthusiasm among medical students ${ }^{(2)}$. However, to date research assessing students' satisfaction after experiencing this combined approach is limited.

The current study aimed to investigate the relationship between satisfaction scores obtained using a validated points system ${ }^{(3)}$ and interest levels of students before and after each event using a five-point numerical scale. Two film events were organized, during which medical students watched a film on a medical topic and subsequently participated in a 30 min discussion led by a medical expert. Film 1 'Super size me' (2004; Kathbur Pictures Inc., USA), which documents the effects of eating only fast-food for 1 month on physical and psychological well-being, was shown in event 1 ( $n$ 26) followed by a discussion on the role of nutrition in disease prevention. Film 2 'Sicko' (2007; The Weinstein Company, New York, USA), which investigates the US healthcare system, particularly in relation to health insurance and the pharmaceutical industry, was shown in event 2 ( $n$ 25) followed by a discussion on health and human rights. The two events were approximately 1 month apart. Data were collected using an anonymous evaluation form, which was composed of 3 sections: demographic information (i.e. discipline and year of study); interest level before and after each event; and four questions assessing medical students' satisfaction. Changes in perceived level of interest before and after each event were analysed using the Wilcoxon matched-pairs signed-ranks test. The correlation between interest level and satisfaction scores was examined using the Spearman's rank correlation coefficient (non-parametric equivalent of Pearson's correlation coefficient).

The possible range for satisfaction scores was -4 to +4 . Results obtained from event 1 ranged from +2 to +4 , with a median of +4 . For event 2 satisfaction scores ranged from +3 to +4 , with a median of +4 . These data suggested that the students were highly satisfied with the events. A significant increase in interest level after each event was also observed $(P<0.001$ for both events). Satisfaction scores were positively correlated with interest level for both events. Interestingly, these results were significant for event $1(P=0.003)$.

These encouraging results suggest that films are an invaluable educational tool in teaching medicine. Despite the small sample size, the results show a significant relationship between students' satisfaction and the increase in perceived interest level. As perceived interest level plays an important role in motivating students, it can be hypothesized that films could play an important role in the future of undergraduate medical education.

1. Weber CM \& Silk H (2007) Lit Arts Med Educ 39, 317-319.

2. Wong V et al. (2009) J Int Assoc Med Sci (In the Press).

3. Sawalha AF, Sweileh WM, Zyoud SH et al. (2008) Complement Ther Med 16, 343-349. 